\title{
Pengembangan Model Keselamatan pada Transportasi Kereta Api (Studi Kasus: PT. Kereta Komuter Indonesia)
}

\section{Development of a Safety Model on Railway Transportation (Case Study: PT. Kereta Komuter Indonesia)}

\author{
Nilla $^{1 *}$, Parwadi Moengin ${ }^{1}$ \\ ${ }^{1}$ Program Studi Teknik Industri, Universitas Trisakti, Jl. Kyai Tapa No. 1, Jakarta Barat 11440, Indonesia
}

Diterima: 18 Februari, 2019 / Disetujui: 1 Agustus, 2019

\begin{abstract}
The application of safety is an important matter in carrying out activities inland transportation including railroad transportation. Jabodetabek travel routes are handled directly by PT. Kereta Komuter Indonesia. This activity certainly requires a lot of human labor so safety is very important in this regard. With the existence of safety arrangements, it will avoid any related things from accidents or losses due to the delay in the completion of work caused by the inaccurate company safety management system. Therefore each element involved in each activity requires further knowledge and understanding of the core factors that are in accordance with the safety management system used. Referring to this approach, research is carried out on the railroad industry in Indonesia by developing a safety model in the railway industry. The research was conducted by finding the right literature and then developing a model for the factors considered appropriate to be applied to the safety management system in railroad transportation in Indonesia. After the model was developed, the model was confirmed by the Confirmatory Factor Analysis (CFA) approach with the Structural Equation Modeling (SEM) method. The results of the study will prove that the factors developed in the safety model are positively related to the implementation of commuter train safety management in Indonesia.
\end{abstract}

Keywords: Safety, Train, Commuter, Structural Equation Modeling

\begin{abstract}
ABSTRAK
Penerapan keselamatan merupakan suatu hal yang penting dalam pelaksanaan aktivitas pada transportasi darat termasuk transportasi kereta api. Aktivitas Jabodetabek yang sangat padat ditangani khusus oleh PT. Kereta Komuter Indonesia. Aktivitas tersebut tentunya banyak membutuhkan tenaga manusia sehingga keselamatan sangat penting dalam hal ini. Dengan adanya pengaturan keselamatan juga akan menghindarkan setiap yang terkait di dalamnya dari kecelakaan ataupun kerugian akibat keterlambatan penyelesaian pekerjaan yang diakibatkan kurang tepatnya sistem manajemen keselamatan perusahaan. Oleh karena itu tiap elemen yang terlibat dalam setiap kegiatan/aktivitas memerlukan pengetahuan dan pemahaman lebih lanjut mengenai faktor inti yang sesuai dengan sistem manajemen keselamatan yang digunakan. Berdasarkan hal tersebut dilakukan penelitian pada industri perkeretaapian di Indonesia dengan mengembangkan model keselamatan pada industri perkeretaapian. Penelitian dilakukan dengan menemukan literatur yang tepat kemudian dilakukan pengembangan model terhadap faktor yang dianggap tepat untuk diterapkan pada sistem manajemen keselamatan pada transportasi kereta api di Indonesia. Setelah model dikembangkan, model tersebut dikonfirmasi dengan pendekatan Confirmatory Factor Analysis (CFA) dengan metode Structural Equation Modeling (SEM). Hasil penelitian akan membuktikan bahwa faktor-faktor yang dikembangkan dalam model keselamatan tersebut berhubungan positif untuk diterapkan dalam manajemen keselamatan kereta komuter di Indonesia.
\end{abstract}

Kata Kunci: Keselamatan, Kereta Api, Komuter, Structural Equation Modeling

\section{PENDAHULUAN}

Kecelakaan merupakan kejadian tak terkontrol atau tak terencanakan disebabkan oleh faktor manusia, situasi, atau lingkungan, yang membuat terganggunya proses kerja dengan atau tanpa berakibat pada cedera, sakit,

*e-mail: nilla@trisakti.ac.id 
kematian, atau kerusakan properti kerja (Colling, 1990). Kecelakaan adalah kejadian yang tidak diinginkan yang terjadi dan menyebabkan kerugian pada manusia dan harta benda (Bird dan Germain, 1996). Menurut UU No. 3 tahun 1992 tentang Jaminan Sosial Tenaga Kerja, kecelakaan kerja adalah kecelakaan yang terjadi berkaitan dengan hubungan kerja, termasuk penyakit yang timbul karena hubungan kerja, demikian pula kecelakaan yang terjadi dalam perjalanan berangkat dari rumah menuju tempat kerja dan pulang ke rumah melalui jalan yang biasa atau wajar dilalui. Penyebab utama kecelakaan adalah prilaku dan kondisi lingkungan kerja yang tidak aman, sehingga perhatian berbagai perusahaan untuk meningkatkan keselamatan perlu dilakukan (Heni, 2011).

Melihat pada angka kecelakaan kerja yang masih tinggi serta kerugian yang timbul akibat terjadinya kecelakaan dalam bekerja maka diperlukan adanya penanganan dengan baik ketika kecelakaan atau insiden terjadi. Selain itu diperlukan juga tindakan preventif untuk upaya pencegahan. Perilaku aman diperlukan untuk pencegahan dan mengurangi tingkat keparahan dan ancaman yang dirasakan dalam bekerja (Goetz et al., 2016). Tindakan preventif sebagai upaya pencegahan kecelakaan juga diperlukan untuk organisasi yang bergerak dalam bidang transportasi seperti kereta komuter. Tingkat keselamatan yang diberikan oleh jasa kereta api sangat berpengaruh kepada jumlah pelanggan atau pengguna jasa transportasi, oleh karena itu pengguna jasa kereta api memerlukan ketegasan atas jaminan keselamatan dalam perjalanan kereta api, disamping kepastian atas ketepatan jadwal dan kecepatan kereta api, penumpang kereta api harus merasa aman dan nyaman terhadap bahaya kecelakaan.

Kereta komuter merupakan jenis transportasi darat yang banyak digunakan oleh masyarakat area Jabodetabek. Berdasarkan data dari Kementrian Perhubungan tercatat sampai dengan tahun 2016 penumpang kereta komuter mencapai sekitar 850.000 orang per hari dan diperkirakan jumlahnya akan naik menjadi 1.200.000 orang pada tahun 2019 mendatang.

Mengingat kereta komuter sebagai jasa angkutan transportasi masal, banyaknya penumpang yang diangkut per harinya maka tindakan yang mengarah pada keselamatan dalam bekerja dan keselamatan penumpang perlu menjadi perhatian khusus. Pada organisasi kereta komuter ini, kondisi kerjanya masih banyak membutuhkan tenaga manusia sehingga faktor keselamatan sangat berpengaruh. Faktor kelelahan, stres, cara berkomunikasi, kurangnya pengetahuan dan kerjasama tim, serta iklim kerja, dapat memengaruhi hasil kerja, sehingga dapat mengakibatkan terjadinya kecelakaan kerja, kerugian pada perusahaan jika terjadi insiden, atau bahkan kecelakaan kereta komuter. Untuk hal seperti terlupa/salah dalam melakukan prosedur kerja dapat mengakibatkan efek yang besar. Ini tidak dapat diatur hanya dengan aturan tertulis, akan tetapi perlu dikaji salah satu caranya yaitu dengan menciptakan perilaku dan budaya keselamatan yang positif pada lingkungan kerja melalui tindakan preventif terhadap kecelakaan. Perilaku aman tersebut harus diterapkan oleh setiap elemen yang terkait pada kereta komuter mulai dari kereta tersebut beroperasi, selesai beroperasi, sampai dengan kereta dirawat pada bagian maintenance kereta. Oleh sebab itu, semua elemen-elemen ini perlu mengetahui faktor inti yang berhubungan dengan keselamatan. Dengan diketahuinya faktor inti tersebut yang dijelaskan melalui suatu model keselamatan pada transportasi kereta komuter maka tiap elemen dan pihak yang terkait diharapkan dapat memahami dan meningkatkan keselamatan dalam bekerja, serta melakukan perbaikanperbaikan yang diperlukan pada tiap bagian. Implementasi dari perbaikan tersebut akan menyebabkan terbentuknya perilaku dan budaya keselamatan yang positif pada tempat kerja yang juga akan berdampak terhadap keselamatan pada perjalanan kereta komuter tersebut.

Beberapa penelitian lain yang telah dilakukan sebelumnya terkait topik ini diawali tentang aspek-aspek yang berpengaruh dalam membentuk keselamatan pada pekerja industri di Israel (Zohar, 1980). Penelitian lain telah membahas tentang Psychology of Safety, dari model yang dihasilkan yaitu faktor pembentuk keselamatan terdiri dari manusia, prilaku, dan lingkungan (Geller, 2001). Terdapat tiga komponen yang berhubungan dengan keselamatan (Cooper, 2000) dan dijadikan sebagai konsep umum mengenai keselamatan, serta banyak dipakai dalam penelitian-penelitian setelahnya. Beberapa penelitian tentang keselamatan telah menunjukkan karakteristik masing-masing industri, antara lain: pengembangan model untuk memprediksi 
perilaku aman dalam bekerja pada perusahaan konstruksi (Guo, Yiu dan González, 2016), model keselamatan pada industri kereta api (Wang et al., 2018), proses operasional untuk menghasilkan keselamatan dengan menggunakan model control prediktif (Albalawi, Durand dan Christofides, 2017). Selain itu, penelitian lain dilakukan untuk menganalisis model keselamatan pada kereta bawah tanah (Rong, Sainan dan Mengshi, 2016) dan menjelaskan tentang model penilaian risiko keselamatan pada kereta api (Leitner, 2017).

\section{METODOLOGI}

Lingkungan pekerjaan dalam organisasi kereta komuter merupakan lingkungan dengan kondisi kerja yang kompleks. Kesalahan atau kelalaian dalam melakukan proses kerja dapat mengakibatkan kerugian terhadap pekerja, perusahaan, dan dalam situasi tertentu dapat juga membahayakan perjalanan dan penumpang.

\subsection{Pengembangan Model}

Dimensi yang terdapat dalam model penelitian berasal dari beberapa model penelitian yang telah dibangun sebelumnya. Pada Gambar 1 ditunjukkan skema langkah pengembangan model berikut rujukan model dasar dan model pendukung yang digunakan dalam penelitian.

$$
\text { Lingkungan dalam organisasi }
$$

perkeretaapian merupakan lingkungan kerja dengan kondisi yang kompleks. Lingkungan kerjanya terdiri dari bermacam bagian yang saling terkait satu sama lain, mulai dari pada saat pengecekan kereta, dan operasional kereta dari kereta berangkat sampai akhir tujuan yang melibatkan semua elemen dalam organisasi perkeretaapian dan penumpang keretanya. Kesalahan ataupun ketidakharmonisan dalam melakukan proses kerja dapat mengakibatkan kerugian pekerja, perusahaan, dan dalam situasi tertentu bahkan dapat membahayakan keselamatan penumpang kereta. Berdasarkan hal-hal tersebut dalam pengembangan model penelitian perlu diperhatikan faktor-faktor yang mencakup semua elemen yang saling berintegrasi dalam aktivitas pada kereta komuter.

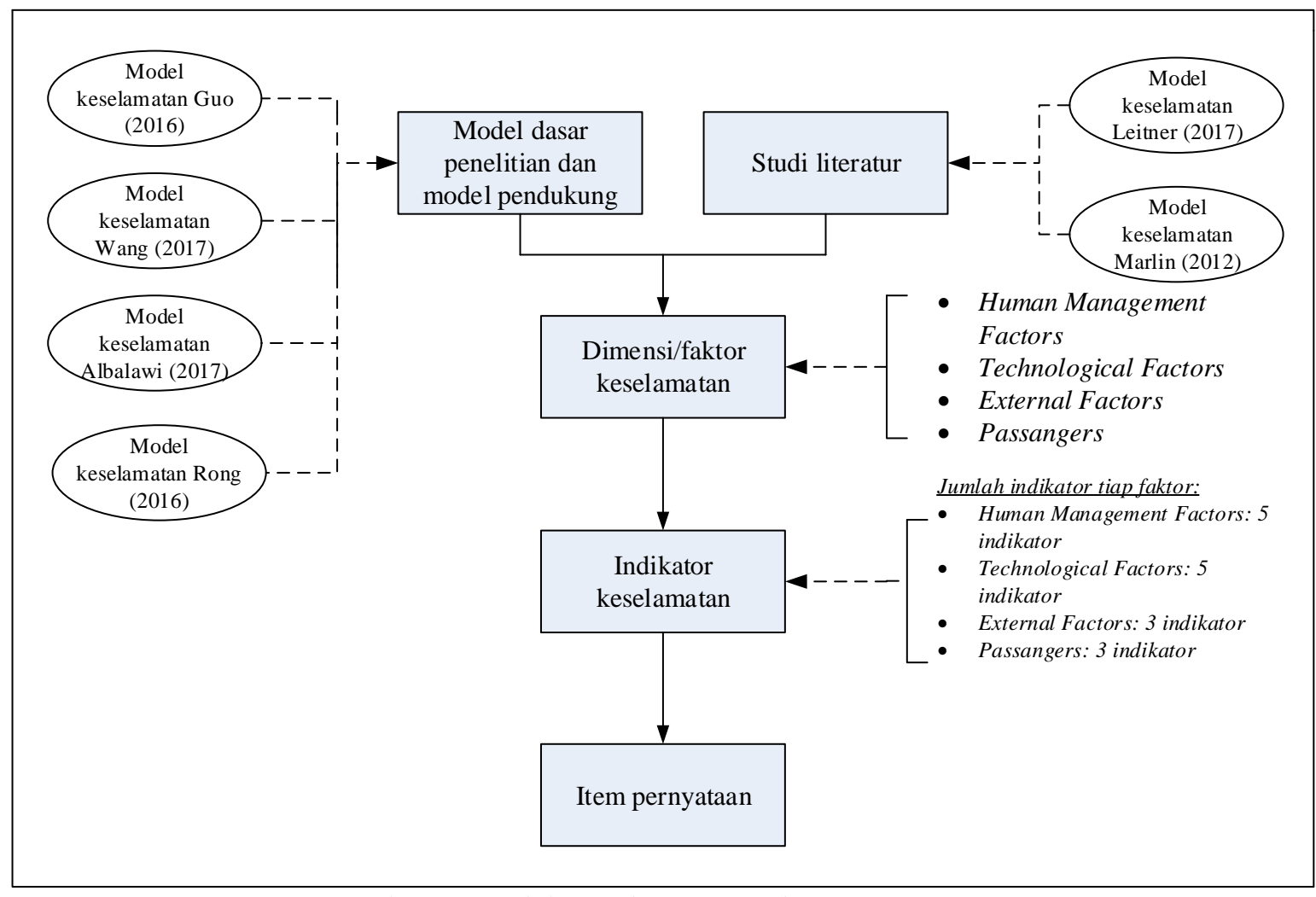

Gambar 1. Model Keselamatan Pada Kereta Komuter 
Gambar 2 merupakan dimensi yang terdapat pada model penelitian yang terkait dengan aktivitas pada kereta komuter, yaitu:

\section{Human Management Factors}

Berkaitan dengan sikap dari manajemen sehubungan dengan keselamatan. Ketika seorang teknisi/operator mencoba untuk menyelesaikan sebuah prosedur, kemungkinan kesalahan itu ada. Dalam mengamati hal-hal yang berpengaruh terhadap teknisi/operator dalam melakukan perawatan, masalah psikologis seperti stress, faktor sosial, dan kemampuan kognitif memainkan peran pada teknisi (Fatima, 2009). Dijelaskan juga bahwa kecelakaan merupakan peristiwa yang tidak berdiri sendiri, tetapi terjadi sebagai akibat dari lingkungan yang diciptakan oleh manajemen.

Berdasarkan keterangan di atas, dapat dikatakan bahwa Human Management Factors diperlukan untuk menciptakan perilaku keselamatan yang positif pada tempat kerja melalui cara-cara yang dilakukan oleh manajemen untuk menciptakan lingkungan kerja yang mendukung terciptanya perilaku keselamatan yang positif dengan pertimbangan terhadap masalah psikologis pekerja.

Indikator dari Human Management Factors adalah:

a. Management safety commitment

Berkaitan dengan komitmen manajemen untuk menempatkan keselamatan sebagai prioritas utama dalam setiap aktivitas yang dilakukan pada organisasi.

b. Social support

Dukungan sosial dalam organisasi terkait keselamatan. Dukungan tersebut meliputi kepedulian tiap-tiap orang dalam lingkungan organisasi, baik atasan terhadap bawahan dan sebaliknya maupun dukungan sesama karyawan untuk menjaga dan meningkatkan keselamatan.

c. Production pressure

Sikap karyawan dalam bekerja untuk tetap bekerja sesuai dengan aturan, kebijakan, dan batasan dalam perusahaan selama hal tersebut tetap sejalan dengan safety.

\section{d. Safety motivation}

Berhubungan dengan motivasi dan kesadaran dari karyawan untuk tetap bekerja dengan memperhatikan kaidah dan nilai-nilai keselamatan.

e. Safety knowledge

Pengetahuan yang dimiliki oleh karyawan terkait dengan keselamatan sehingga karyawan mengetahui risiko yang terdapat di tempat kerja dan risiko pekerjaan terhadap keselamatan orang banyak sehingga karyawan mengerti tentang bagaimana menjaga dan mengembangkan perilaku safety dalam organisasi.

\section{Technological Factors}

Berkaitan dengan aktivitas operasional, pengetahuan, pengontrolan, perawatan, penggunaan mesin-mesin dan tools, serta kegiatan teknis lainnya yang berhubungan dengan keselamatan.

Indikator dari Technological Factors:

a. Safety qualification test

Memastikan bahwa mesin, aplikasi, peralatan, dan perlengkapan yang digunakan dalam bekerja dan beroperasi layak untuk digunakan.

b. Rules, conditions, constraints

Aturan, kondisi, dan batasan terkait keselamatan dalam melakukan suatu aktivitas pekerjaan dapat dimengerti dan dipahami dengan baik

c. Safely system

Sistem yang ada dapat beroperasi dengan baik dan aman walaupun dipengaruhi oleh faktor-faktor yang tidak terduga.

d. Safety target

Jika terjadi suatu kesalahan dalam melakukan pekerjaan, maka perbaikan yang dilakukan harus tetap memperhatikan kaidah keselamatan.

e. Correct functional operation

Kegiatan operasional yang meliputi kontrol, perawatan, peralatan \& perlengkapan, dan mesin-mesin, dilakukan secara benar dengan tetap memperhatikan keselamatan.

\section{Faktor Eksternal}

Faktor eksternal merupakan aktivitas yang dilakukan dalam organisasi, seperti kondisi sulit yang terjadi diluar kondisi normal seperti bencana alam, huruhara, dan lain-lain. Jika terjadi kondisi sulit ini hendaknya semua 
aktivitas yang dilakukan tetap memperhatikan keselamatan.

Indikator dari External Factors:

a. Ilegal action

Jika terjadi kondisi sulit seperti bencana ataupun huruhara, jika terpaksa melakukan illegal action, hal tersebut hendaknya dilakukan dengan tetap memperhatikan keselamatan semua elemen yang terkait.

b. Substandar climate

Alternatif tindakan diperlukan untuk mengatasi cuaca ekstrim

c. Emergency condition

Kondisi darurat mungkin saja terjadi, oleh karena itu diperlukan persiapan untuk mengatasi kondisi darurat tersebut (alarm, sistem kontrol, dll)

4. Penumpang

Penumpang merupakan elemen penting dari keseluruhan aktivitas yang dilakukan pada perusahaan. Keselamatan penumpang sebagai pelanggan perlu selalu dijaga.

Indikator dari Passanger:

a. Passanger safety consciousness

Perlu upaya dari pihak manajemen perusahaan untuk dapat menumbuhkan kesadaran penumpang kereta komuter terhadap keselamatan.

b. Environment and equipment

Pihak manajemen perusahaan melakukan usaha terkait keselamatan penumpang dengan menyediakan sarana dan prasarana yang mendukung hal tersebut.

c. Management safety propaganda

Safety propaganda merupakan suatu cara aktif pihak manajemen perusahaan untuk menjaga keselamatan penumpang. Safety propaganda ini dapat dilakukan melalui: $\mathrm{TV}$, media, buletin, forum, internet, dll.

\subsection{Estimasi Model}

Dimensi terbagi atas 4 yaitu: human management factors, technological factors, external factors, dan passanger. Pengujian dilakukan menggunakan SPSS 19.0 dengan pendekatan metode korelasi spearman. Dalam korelasi Spearman Rank, data yang dikorelasikan adalah data ordinal. Data yang ada dalam penelitian ini adalah dalam bentuk ordinal, sehingga digunakan metode korelasi spearman untuk pengujian validitas (Sugiyono, 2011). Korelasi dinyatakan semakin kuat jika nilai koefisien korelasinya mendekati 1 , dengan nilai signifikansinya $(<0,05)$.

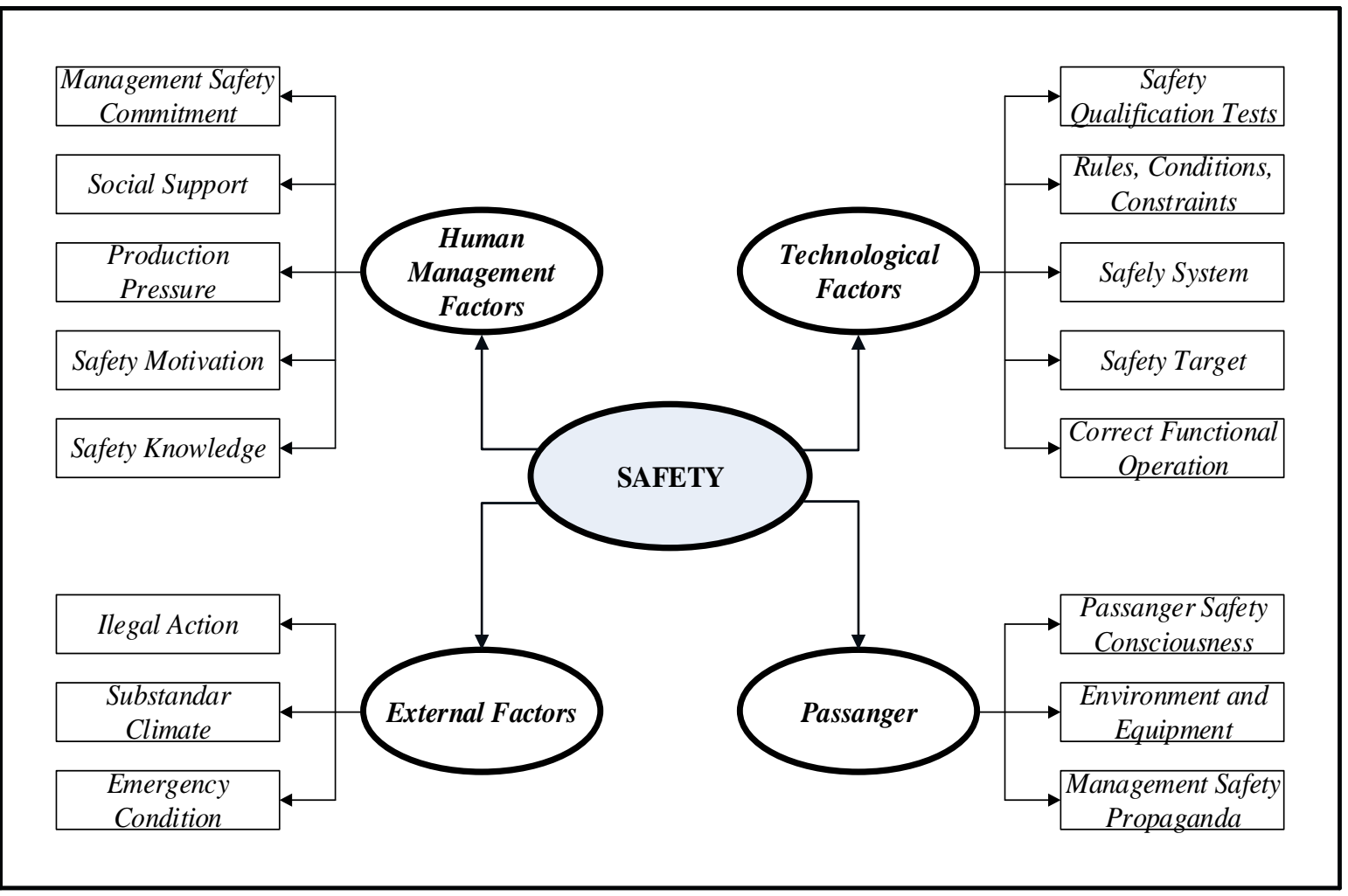

Gambar 2. Model Keselamatan Pada Kereta Komuter 
Uji reliabilitas ini dilakukan dengan menghitung nilai cronbach's alpha. Uji reliabilitas menggunakan nilai cronbach's alpha sebesar 0,7. Angka cronbach's alpha pada kisaran 0,70 adalah dapat diterima, dan di atas 0,80 dikatakan baik (Sekaran dan Bougie, 2016).

Asumsi yang paling fundamental dalam analisis multivariat adalah normalitas (Hair et al., 2014). Apabila asumsi normalitas tidak terpenuhi dan penyimpangan normalitas tersebut besar, maka seluruh uji statistik adalah tidak valid karena penghitungan uji $t$ dan lain sebagainya, dihitung dengan asumsi data normal (Ghozali, 2008).

Dalam penelitian ini, uji normalitas dilakukan dengan menggunakan perangkat lunak LISREL 8.72. Uji normal ini terpenuhi jika p-value dari skewness dan kurtosis besar dari 0,05 (Ghozali, 2008). Berdasarkan skor yang didapat disimpulkan bahwa data berdistribusi normal secara univariat dan multivariat. Model hasil running dengan Lisrel dapat dilihat pada Gambar 3.

\subsection{Uji Kecocokan Model}

Uji kecocokan ini dilakukan untuk menilai kecocokan antara kovarians sampel/data dengan kovarians yang diprediksi oleh model. Uji kecocokan dilakukan dengan melihat pada nilai Goodness of Fit yang terdapat pada output program yang dijalankan. Berdasarkan hasil uji kecocokan ini dapat dilihat apakah model yang diusulkan baik atau tidak. Nilai uji kecocokan yang baik menandakan bahwa semakin sedikit perbedaan antara matrik kovarians sampel dengan matrik kovarians model (Wijanto, 2008). Uji kecocokan dibagi menjadi 3 bagian, yaitu (Hair et al., 2014):

1. Ukuran kecocokan absolut (absolute fit measures)

Ukuran kecocokan absolut menentukan derajat prediksi model keseluruhan (model struktural dan pengukuran) terhadap matrik korelasi dan kovarian. Ukuran yang biasa digunakan untuk mengevaluasi SEM adalah: chi-square, NCP, SNCP, GFI, RMR, RMSEA, ECVI.

2. Ukuran kecocokan inkremental (incremental fit measures)

Ukuran kecocokan inkremental membandingkan model yang diusulkan dengan model dasar. Model dasar ini adalah model dimana semua variabel di dalam model bebas (semua korelasi diantara variabel adalah nol) (Byrne, 2016). Ukuran yang biasa digunakan untuk mengevaluasi SEM adalah: AGFI, TLI/NNFI, NFI, RFI, CFI.

3. Ukuran kecocokan parsimoni (parsimonius fit measures)

Model dengan parameter relatif sedikit (degree of freedom relatif banyak) sering dikenal sebagai model yang mempunyai parsimony/kehematan tinggi. Sedangkan model dengan banyak parameter dapat dikatakan model yang kompleks dan kurang parsimoni. Ukuran kecocokan parsimoni mengaitkan GOF (Goodness of Fit) model dengan jumlah parameter yang diestimasi, yakni yang diperlukan untuk mencapai kecocokan pada tingkat tersebut. Ukuran yang biasa digunakan untuk mengevaluasi SEM adalah: PNFI, PGFI, Normed chisquare, AIC, CAIC.

Pada penelitian ini nilai Goodness of Fit model dapat dikatakan baik dengan berpedoman pada 3 pengujian kecocokan model seperti yang telah dijelaskan sebelumnya.

\subsection{Respesifikasi Model}

Tahap respesifikasi model ini tidak dilakukan karena tidak ada indikator yang dikeluarkan dari model, artinya semua indikator valid dan reliabel untuk mengukur keselamatan. 


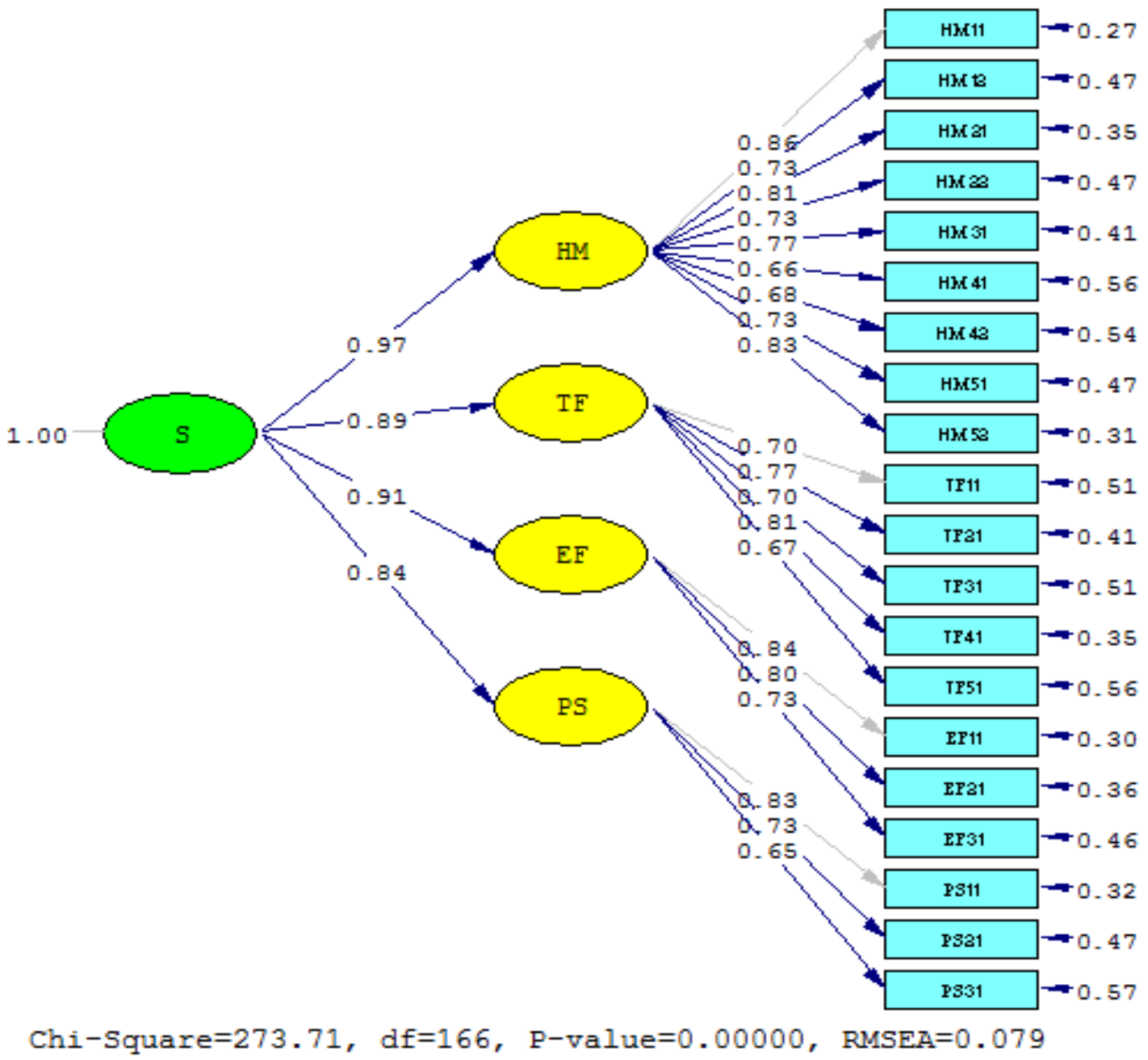

Gambar 3. Model Keselamatan (Running Lisrel)

\section{HASIL DAN PEMBAHASAN}

Penelitian ini menghasilkan temuan dan implikasi manajerial terkait pemahaman dan peningkatan keselamatan secara positif yang penting untuk diperhatikan. Penelitian ini menghasilkan model keselamatan pada organisasi perkeretaapian. Aspek ini menjadi kasus penelitian karena: keselamatan berhubungan dengan fase perkembangan dan pertumbuhan organisasi (Atak dan Kingma, 2011). Organisasi merupakan kesatuan dinamik yang kompleks dan keselamatan hanya merupakan salah satu aspek fungsionalnya. Oleh karena itu perlu dikembangkan aspek yang sesuai untuk melakukan analisis keselamatan dalam organisasi (McDonald et al., 2000). Penelitian ini memperjelas dimensi dari keselamatan, dimana sebelumnya belum terlalu banyak dijelaskan secara detail mengenai keselamatan khususnya pada kereta api. Hasil temuan dalam penelitian ini dapat digunakan lebih lanjut oleh bagian Quality Control perusahaan untuk merencanakan, merancang, dan mempersiapkan strategi dan perbaikan apa yang perlu dilakukan untuk meningkatkan pemahaman semua pihak yang terkait tentang keselamatan serta menciptakan iklim keselamatan yang positif di dalam organisasi.

Dari hasil penelitian ditemukan bahwa Human Management Factors memberikan dampak yang paling besar terhadap keselamatan (97\%). Aspek dari Human Management Factors ini yang paling berpengaruh adalah management safety commitment. Dijelaskan bahwa partisipasi dan keterlibatan pihak manajemen dalam aktivitas yang berhubungan dengan keselamatan dalam bekerja dilakukan sesering mungkin, serta komunikasi informal antara pekerja dengan pihak manajemen dinilai sebagai prilaku yang kritis (O'Connor et al., 2011). Salah satu fase dalam proses pengembangan keselamatan adalah komitmen manajemen. Konstruk yang 
paling umum dalam setiap pembahasan dengan survey adalah persepsi prilaku dan sikap pihak manajemen/supervisor mengenai keselamatan. Komitmen manajemen merupakan atribut yang sangat penting, karena berhubungan dengan pengembangan iklim keselamatan secara positif. Manajemen harus mengetahui kinerja bawahannya dan mencoba menanamkan tentang bagaimana kinerja memengaruhi keselamatan, dan bagaimana organisasi menyediakan sumberdaya untuk dapat bekerja secara aman. Manajemen harus menunjukkan komitmen mereka melalui prilaku, sikap terhadap keselamatan, alokasi sumberdaya, termasuk waktu yang dihabiskan dalam upaya peningkatan keselamatan (Grecco et al., 2014).

$$
\text { Safety knowledge merupakan }
$$

pengetahuan yang dimiliki oleh karyawan terkait dengan keselamatan sehingga karyawan mengetahui risiko yang terdapat di tempat kerja dan risiko pekerjaan terhadap keselamatan orang banyak sehingga karyawan mengerti tentang bagaimana menjaga dan mengembangkan perilaku safety dalam organisasi. Salah satunya dapat dilakukan melalui training keselamatan terhadap karyawan. Ketika dihadapkan pada tugas atau pekerjaan baru yang harus diselesaikan, karyawan merasa sangat perlu untuk mendapatkan training yang cukup terhadap tugas tersebut secara aman. Cara lain yaitu dengan mengadakan simulasi terhadap situasi darurat pada karyawan terkait di organisasi kereta api maupun di stasiun.

Faktor kedua terpenting yang perlu diperhatikan yaitu External Factors. Jika terjadi kondisi sulit seperti bencana ataupun huruhara, jika terpaksa melakukan illegal action, hal tersebut hendaknya dilakukan dengan tetap memperhatikan keselamatan semua elemen yang terkait. Kasus tawuran pelajar serta pelemparan batu ke kaca gerbong kereta terkadang masih saja terjadi. Untuk kondisi seperti ini jika kereta dengan terpaksa harus berhenti secara tiba-tiba, segala sesuatunya tetap harus dengan pertimbangan faktor keselamatan sebagai hal yang terpenting.

Selanjutnya yang perlu diperhatikan dalam pemahaman dan peningkatan terhadap keselamatan ini adalah Technological Factor. Komputerisasi merupakan kunci penting dalam tren industri belakangan ini, praktek perkembangan teknologi tersebut makin meluas pada sektor pembangunan kota, pendidikan, dan transportasi, perkembangan teknologi menuntut pengembangan terhadap kemampuan personelnya (Joe dan Chang, 2017). Setiap elemen yang terlibat harus dapat menyesuaikan perkembangan teknologi yang digunakan pada pekerjaannya, oleh karena itu jika terjadi kesalahan dalam melakukan pekerjaan, maka penting dalam perbaikan yang dilakukan harus tetap memperhatikan kaidah keselamatan. Semua aturan, kondisi, dan batasan terkait keselamatan dalam melakukan suatu aktivitas pekerjaan dapat dimengerti dan dipahami dengan baik.

Faktor keempat yang penting untuk dibahas adalah Passanger (PS). Penumpang merupakan elemen penting dari keseluruhan aktivitas yang dilakukan pada perusahaan. Keselamatan penumpang sebagai customer perlu selalu dijaga (Rong, Sainan dan Mengshi, 2016). Kesadaran penumpang terhadap keselamatan adalah salah satu kunci terpenting untuk menciptakan iklim keselamatan yang positif terhadap penumpang kereta. Pihak manajemen kereta api dianggap perlu untuk dapat mewujudkan hal ini, salah satunya dengan mengingatkan penumpang dengan berbagai cara akan risiko apa saja yang bisa terjadi baik di peron stasiun ataupun di dalam kereta itu sendiri. Penyediaan sistem keselamatan yang mendukung serta sarana dan prasarana juga akan membantu terwujudnya iklim keselamatan positif terhadap penumpang kereta api.

\section{SIMPULAN}

Human Management Factors yang terdiri dari komitmen manajemen terhadap keselamatan, dukungan sosial antar rekan kerja, sikap karyawan terhadap tekanan kerja, serta motivasi dan pengetahuan tentang keselamatan. Technological Factors yang terdiri dari perkembangan dan kelayakan teknologi yang digunakan, kebijakan mengenai peralatan dan mesin yang digunakan, sistem keselamatan dalam penggunaan mesin dan peralatan, serta pengontrolan penggunaan mesin dan peralatan Peer Support yang terdiri dari mengingatkan satu sama lain, umpan balik positif. External Factors yang terdiri dari alternatif tindakan terhadap kondisi darurat dan sarana prasarana untuk kondisi darurat. Passanger yang terdiri dari kesadaran penumpang terhadap keselamatan dan usaha pihak manajemen untuk menciptakan iklim yang selamat untuk penumpang kereta api. 


\section{DAFTAR PUSTAKA}

Albalawi, F., Durand, H. dan Christofides, P. D. (2017) "Process Operational Safety Using Model Predictive Control Based on a Process Safeness Index," Computers and Chemical Engineering, 104(September), hal. 76-88. doi: 10.1016/j.compchemeng.2017.04.010.

Atak, A. dan Kingma, S. (2011) "Safety Culture in an Aircraft Maintenance Organisation: A View from the Inside," Safety Science, 49(2), hal. 268-278. doi: 10.1016/j.ssci.2010.08.007.

Bird, F. E. dan Germain, G. L. (1996) Practical Loss Control Leadership. International Loss Control Institute.

Byrne, B. M. (2016) Structural Equation Modeling with Amos. 3 ed. New York: Routledge.

Colling, D. A. (1990) Industrial Safety: Management and Technology. 1 ed. Prentice Hall.

Cooper, M. D. (2000) "Towards a Model of Safety Culture," Safety Science, 36, hal. 111-136.

Fatima, J. (2009) A Safety Survey Amongst Aircraft Maintenance Engineers at $A$ Leading Airline in South Africa. University of Stellenbosch.

Geller, E. S. (2001) The Psychology of Safety Handbook. Boca Raton: CRC Press.

Ghozali, I. (2008) Structural Equation Modeling: Teori, Konsep, dan Aplikasi Dengan Program Lisrel 8.80. Semarang: Badan Penerbit Universitas Diponegoro.

Goetz, A. R. et al. (2016) "The Functional Value of Preventive and Restorative Safety Behaviors: A Systematic Review of the Literature," Clinical Psychology Review, 44, hal. 112-124. doi: 10.1016/j.cpr.2015.12.005.

Grecco, C. H. dos S. et al. (2014) "Safety Culture Assessment: A Fuzzy Model for Improving Safety Performance in a Radioactive Installation," Progress in Nuclear Energy, 70, hal. 71-83. doi: 10.1016/j.pnucene.2013.08.001.

Guo, B. H. . W., Yiu, T. W. dan González, V. A. (2016) "Predicting Safety Behavior in the Construction Industry: Development and Test of an Integrative Model," Safety Science, 84, hal. 1-11. doi: 10.1016/j.ssci.2015.11.020.

Hair, J. F. et al. (2014) Multivariate Data Analysis. 7 ed. London: Pearson Education Limited.

Heni, Y. (2011) improving Our Safety Culture. Jakarta: PT. Gramedia Pustaka Utama.

Joe, T. dan Chang, H. (2017) "A Study on UserOriented and Intelligent Service Design in Sustainable Computing: A Case of Shipbuilding Industry Safety," Sustainability, 9(4), hal. 1-19. doi: 10.3390/su9040544.

Leitner, B. (2017) "A General Model for Railway Systems Risk Assessment with the Use of Railway Accident Scenarios Analysis," Procedia Engineering, 187, hal. 150-159. doi: 10.1016/j.proeng.2017.04.361.

McDonald, N. et al. (2000) "Safety Management Systems and Safety Culture in Arcraft Maintenance Organisations," Safety Science, 34(1-3), hal. 151-176. doi: 10.1016/S0925-7535(00)00011-4.

O'Connor, P. et al. (2011) "Measuring Safety Climate in Aviation: A Review and Recommendations for the Future," Safety Science, 49(2), hal. 128-138. doi: 10.1016/j.ssci.2010.10.001.

Rong, G., Sainan, W. dan Mengshi, H. (2016) "Underground Railway Safety Analysis and Planning Strategy: A Case of Harbin Metro Line 1, China," Procedia Engineering, 165, hal. 575-582. doi: 10.1016/j.proeng.2016.11.753.

Sekaran, U. dan Bougie, R. (2016) Research Methods for Business. 7 ed. Chichester: John Wiley \& Sons.

Sugiyono (2011) Metode Penelitian Kuantitatif Kualitatif dan $R \& D$. Bandung: Alfabeta.

Wang, R. et al. (2018) "Modelling Confidence in Railway Safety Case," Safety Science, 110(October), hal. 286-299. doi: 10.1016/j.ssci.2017.11.012.

Wijanto, S. H. (2008) Structural Equation Modeling Dengan Lisrel 8.8 Konsep \& Tutorial. Yogyakarta: Graha Ilmu.

Zohar, D. (1980) "Safety Climate in Industrial Organizations: Theoretical and Applied Implications," Journal of Applied Psychology, 65(1), hal. 96-102. doi: 10.1037/0021-9010.65.1.96. 